\title{
Combining non-pharmacological treatments with pharmacotherapies for neurological disorders: a unique interface of the brain, drug-device, and intellectual property
}

\section{Grzegorz Bulaj *}

Department of Medicinal Chemistry, Skaggs Pharmacy Institute, College of Pharmacy, University of Utah, Salt Lake City, UT, USA

Edited by:

Fernando Cendes, University of Campinas, Brazil

\section{Reviewed by:}

Jose F. Tellez-Zenteno, University of Saskatchewan, Canada

Marino M. Bianchin, Universidade

Federal do Rio Grande do Sul, Brazil

\section{*Correspondence:}

Grzegorz Bulaj, Department of Medicinal Chemistry, Skaggs

Pharmacy Institute, College of

Pharmacy, University of Utah, 30

South 2000 East, Salt Lake City,

UT 84112, USA

e-mail: bulaj@pharm.utah.edu
Mobile medical applications (mHealth), music, and video games are being developed and tested for their ability to improve pharmacotherapy outcomes and medication adherence. Pleiotropic mechanism of music and gamification engages an intrinsic motivation and the brain reward system, supporting therapies in patients with neurological disorders, including neuropathic pain, depression, anxiety, or neurodegenerative disorders. Based on accumulating results from clinical trials, an innovative combination treatment of epilepsy seizures, comorbidities, and the medication non-adherence can be designed, consisting of antiepileptic drugs and disease self-management software delivering clinically beneficial music. Since creative elements and art expressed in games, music, and software are copyrighted, therefore clinical and regulatory challenges in developing copyrighted, drug-device therapies may be offset by a value proposition of the exclusivity due to the patent-independent protection, which can last for over 70 years. Taken together, development of copyrighted non-pharmacological treatments (e-therapies), and their combinations with pharmacotherapies, offer incentives to chronically ill patients and outcome-driven health care industries.

Keywords: chronic disease, psychiatric disorders, dopamine, Mozart, epilepsy, depression, fatigue

\section{INTRODUCTION}

Mobile medical applications (mHealth apps) emerge as daily companions to help patients, clinicians, and pharmacists (1-10). There is a growing number of self-management applications including those for chronic pain $(11,12)$, asthma $(13)$, or mental health $(14,15)$. One example of an FDA-cleared mobile therapy is BlueStar ${ }^{\circledR}$, the clinical and behavioral self-management platform for patients with type 2 diabetes, which was shown to improve control of glucose blood levels (16-18). Mobile medical applications cleared by the FDA range from diagnostic and monitoring platforms to a sound therapy or interactive medication reminders (19). The FDA intends to exercise enforcement discretion for mobile medical applications, which aim to help patients with disease selfmanagement or medication adherence, while those intended to perform medical device functions, may require approval or clearance (2). The exponential growth of mobile medical applications has resulted in a lag of reports from larger scale, randomized controlled trials (RCTs) to support their clinical utilities $(3,20)$.

Interactive technologies targeting healthy behaviors and therapy outcomes include video games (21). Clinical utility of serious video games (e-therapies or therapeutic games) has been studied in patients with various chronic conditions including depression,

Abbreviations: AEDs, antiepileptic drugs; FDA, Food and Drug Administration; IP, intellectual property; NSAIDS, non-steroidal anti-inflammatory drugs; PMA, premarket approval; RCTs, randomized controlled trials.
Parkinson's disease, asthma, diabetes, cancer, or stroke (22-26). Table S1 in Supplementary Material provides examples of mobile apps and games for the treatment of depression, anxiety, dementia, pain, attention deficit hyperactivity disorder (ADHD), and cerebral palsy. One example of a serious video game is "ReMission," a game specifically designed for cancer patients and shown to improve behavioral outcomes, cancer-related knowledge, and medication adherence during chemotherapy in adolescent patients with acute leukemia, lymphoma, and soft-tissue sarcoma $(27,28)$. In RCTs, playing video games was found to be clinically effective in treating depression $(25,29)$. The use of video games to modulate the brain neuroplasticity also improved age-related neuronal deficits and enhanced cognitive functions in older adults (30). Video games are explored as a preventive medicine strategy against HIV infections (31), or obesity (32). Fun and game-based principles (gamification) in serious video games are important elements when targeting intrinsic motivation to improve health behaviors (21). In 2014, the FDA cleared a motion-capture video game, developed by Jintronix as a rehabilitation system for stoke patients, or those with traumatic brain injury.

Music has been applied as a non-pharmacological treatment mainly for neurological conditions. The pleiotropic nature of music is mediated by neurochemical changes in the brain, endocrinological, and immune systems (33-35). A therapeutic potential of music to treat psychiatric disorders was recently 
reviewed (33). Recent studies show clinical applications of music for epilepsy patients $(36,37)$, including listening to the Mozart K.448 sonata, which was shown to reduce frequency of epileptiform discharges (38-43), and to reduce seizure frequencies (40, $43,44)$. Music-supported therapies include indications such as pain $(45-48)$, stroke $(49,50)$, dementia $(51,52)$, depression $(53)$, or anxiety $(54,55)$. A therapeutic music video intervention was shown to improve resilience in cancer patients being treated with hematopoietic stem cells (56). Given popularity and convenience of listening to music, this non-pharmacological treatment can be easily incorporated into mobile medical applications.

Over the last decade, it has been recognized that a significant number of patients with chronic diseases fail to take medications as prescribed $(57,58)$. Medication non-adherence is considered as a serious global health care problem (59). While clinical aspects of medication adherence are studied, economic costs of medication non-adherence are estimated as \$100-290 billion per year in additional medical spending paid by the US health care (57) and $\$ 564$ billion in lost revenues of the global pharmaceutical industry (60). Current strategies to improve medication adherence include less frequent dosing, extended-release formulations, novel drug delivery devices, providing external incentives, or support-based interventions. Medication non-adherence is a patient behavioral aspect associated with all chronic diseases. Health care industry is embracing gamification and electronic platforms in patient care (61). Clinical studies of mobile medical applications, serious video games, or music show their promise as tools to improve therapy outcomes, disease self-management, or medication adherence for chronically ill patients (Figure 1A). This article discusses opportunities for creating and clinical development of non-pharmacological treatments, which can be integrated into specific combination therapies for chronic diseases.

\section{INTEGRATING GAMIFICATION AND MUSIC INTO THERAPIES - DOPAMINERGIC CONNECTIONS}

FDA-cleared mobile and video game therapies, such as BlueStar ${ }^{\circledR}$ and Jintronix Rehabilitation System, show new opportunities to integrate drugs with devices, thereby bridging pharmacotherapies with disease self-management. Figure 1B shows an example of pharmacotherapy in combination with a mobile platform for the treatment of diabetes. Since studies encourage clinical use of music for pain relief $(48,62,63)$, parallel needs for more personalized treatments of neuropathic pain and for improving pain relief (64) can be addressed by a combination of an appropriate analgesic and pain self-management platforms with music and games for pain relief. Therapeutic interactive voice response has been shown to reduce use of opioids and non-steroidal antiinflammatory drugs (NSAIDs) (65). Cancer patients may benefit from combining chemotherapy with a serious video game, such as "Re-Mission" $(27,28)$ or the Patient Empowerment Exercise Video Game (22) which target comorbidities including depression, anxiety, or fatigue. Gamification is a tool to engage intrinsic motivation using such features as choice and decision-making, levels and challenge, fantasy and curiosity (66). Therapeutic video games and self-acquired rewards engage the brain reward system in active players $(67,68)$, therefore integrating gamification into self-management platforms is also useful for motivating and

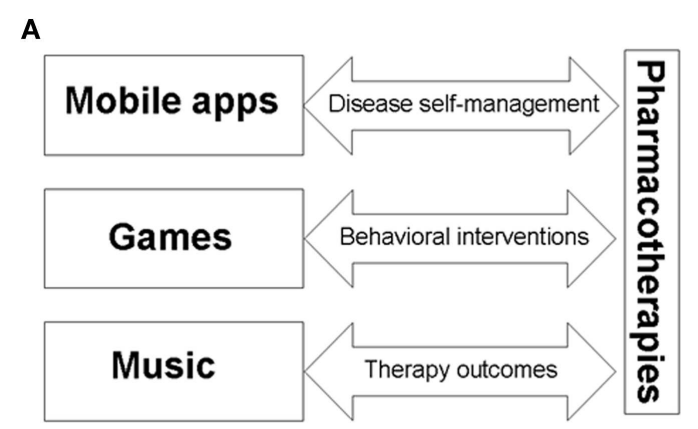

B

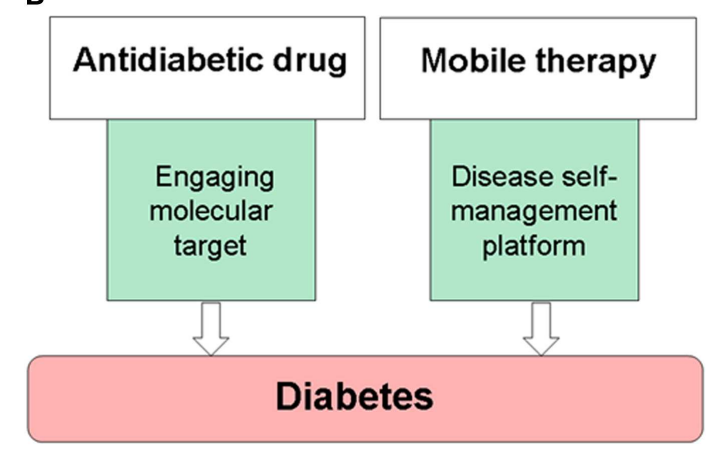

FIGURE 1 | Examples of drug-device interfaces created by mobile medical applications, serious video games, or music. (A) Electronic devices are used to provide music, games, and mobile medical applications, while also becoming delivery systems for disease self-management platforms. (B) An example of combining pharmacotherapies with medical devices for the treatment of diabetes. Mobile therapies, such as BlueStar $\circledast$, can support disease-specific, healthy behaviors of a patient, and remind about taking prescribed medications on-time.

rewarding patients while learning and reinforcing disease-specific healthy habits.

Studies on physiological effects of music and games begin to indicate multiple effects on the nervous and endocrine systems, including music-induced modulation of various neurotransmitters and hormones $(34,35)$. An overlapping mechanism of gaming and music includes activation of the mesolimbic system and dopaminergic neurotransmission in the brain (67-72). Game- or music-evoked dopamine release involving dopamine D2 receptors was shown by positron emission tomography using 11C-labeled raclopride $(69,71)$. Table S2 in Supplementary Material provides examples of functional magnetic resonance imaging (fMRI) studies aimed to elucidate music or games mechanism of actions. Both gaming and music activate nucleus accumbens in the mesolimbic reward circuitry, as well as parts of prefrontal cortex $(67,68$, $72,73)$. Mesolimbic dopamine plays important roles in learning and motivation $(74,75)$, thus activation of the dopaminergic signaling by therapeutic games or/and tailored music can facilitate behavioral and pharmacological interventions in patients. Targeting the dopamine system by playing video games improved symptoms in schizophrenia patients (76), whereas clinical studies of games for depression (25) or Parkinson's disease $(24,77)$, encourage similar strategies for migraines or addiction. Taken 
together, the dopaminergic mechanisms of music and games offer opportunities for coupling the pleasurable brain reward system with intrinsic motivation and the formation of healthy habits, resulting in unique disease self-management platforms. Given pleiotropic effects of music and games, mechanism-based combinations of these non-pharmacological treatments with specific drugs can improve therapy outcomes for various neurological diseases.

\section{REDEFINING A COMBINATION THERAPY FOR EPILEPSY}

Designing innovative drug-device combination therapies can be illustrated using the treatment of epilepsy. Managing epilepsy is challenging due to: (i) significant resistance to antiepileptic drugs (AEDs), (ii) compromised medication adherence, and (iii) significant prevalence of comorbidities, such as anxiety or depression (78). Despite many AEDs approved for the treatment of epilepsy (Figure 2A), estimated 25-40\% of patients with epilepsy are refractory to current AEDs (79). An approximate 50-60\% medication adherence rate among epilepsy patients results in increased risks of seizures and mortality (80-82), while the main comorbidity, depression, is also difficult to treat with antidepressant drugs (83). To help epilepsy patients with disease selfmanagement, currently available mobile devices include a SmartWatch, which is capable of detecting movements associated with seizures, as well as mobile applications helping to self-report and record seizures, manage medications, or learn more facts about epilepsy.

Accumulating clinical evidence suggests that listening to the Mozart's K.448 results in reduction of generalized and focal seizures in epilepsy patients $(36,37)$. The K.448 was also effective in reducing seizure frequencies in children with pharmacoresistant epilepsy (84), and in patients following their first unprovoked seizures (43). Using simultaneous electroencephalogram and electrocardiogram recordings, the reduction of epileptiform discharges by K.448 and K.545 was shown to be accompanied by activation of the parasympathetic system (42). While an anticonvulsant mechanism of action for audiogenic stimulation remains unknown, reports also suggest a role of mirror neurons or/and neurotransmitters pathways including the dopaminergic system $(36,37)$. Genetic, pharmacological, and imaging studies support the dopamine signaling in epilepsy and epileptogenesis, including D2 receptors (85-88).

To improve pharmacotherapy, manage comorbidities and medication adherence for epilepsy patients, the drug-device combination therapy can include a specific AED and a matching medical device delivering non-pharmacological elements (Figure 2B). The most apparent non-pharmacological component could be music, which reduces seizures [such as the Mozart's K.448 or K.545 (41)]. To treat symptoms of depression or anxiety, often experienced by epilepsy patients, the self-management platform can include a game comprising cognitive behavioral therapy elements (29), or even a combination of music and games as musical games. Such platforms may also help manage seizure-precipitating stress by modulating cortical responses (89). Noteworthy, a longterm stimulation of nucleus accumbens can decrease seizure severity (90), while integrating music into the treatments of

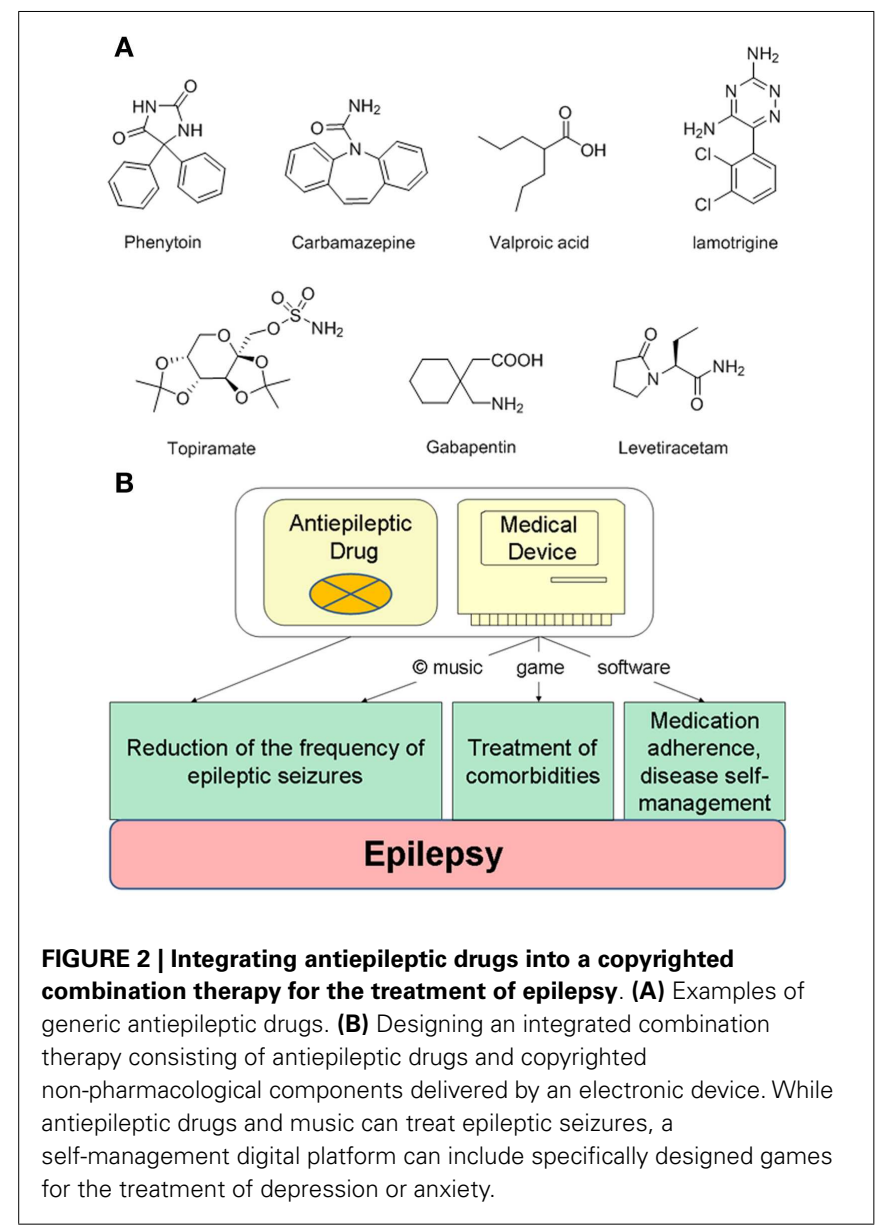

epilepsy comorbidities was recently emphasized (91). Additional non-pharmacological components delivered by the medical device can include medication adherence reminders and other features to self-report and track seizures. This integrated treatment may appeal to pediatric epilepsy patients, since non-adherence to AEDs within the first 6 months significantly affects long-term rates of becoming seizure-free (92).

Creating therapeutic music to reduce epileptic seizures extends to translational research, since music can be subject to preclinical screening [for example, in such indications as addiction (93)]. In animal testing, exposure to the Mozart K.448 resulted in: (i) reduction of spontaneous absence seizure and high-voltage rhythmic spike discharges in Long Evans rats (94), (ii) increased dopamine levels in rat brains (95), and (iii) decreased corticosterone $(95,96)$. Positive effects of the K.448 music on spatial-temporal learning were reported for rats and mice (97-99). Since clinical data suggest that K.448 can reduce seizures in patients with refractory epilepsy (84), studies on interactions between K.448 and AEDs in animal models of epilepsy may help to elucidate the mechanism of action of K.448 while increasing the potency of the AEDs. Comparing preclinical and clinical effects of music in other medical indications, such as depression, anxiety, addiction, or neurodegenerative disorders may validate the translational research for using specific auditory stimulations with drugs. 


\section{COPYRIGHTS AS INCENTIVES FOR CREATING NON-PHARMACOLOGICAL TREATMENTS}

An incentive for creating and clinical development of nonpharmacological therapies can be their copyrighted works, which are protected by the intellectual property (IP) law. Unlike patents protecting ideas, copyright protects the expression of an idea found in creative elements and art found in digital media, software, electronic games, and music. In the US, the Copyright Act of 1976 offers the benefit a long-term protection lasting not less than 70 years, and up to 120 years. Copyright protection is automatic as soon as it is created, although a copyright registration offers legal advantages in case of any future infringements. Furthermore, copyright is recognized and protected in most countries under national and international law through the Universal Copyright Convention and the Berne Convention which the US joined as a member in 1955 and 1989, respectively.

In a web-based era, developing games or music intended for clinical use create opportunities for "off-label" uses, whereas classical music which exists in public domain (such as Mozart's K.448 or K.545 sonatas) presents the exclusivity challenge. Re-recording of specific pieces of classical music may offer recording copyrights, while re-composing and modifying individual pieces of publicdomain music intended for clinical development may offer an additional level of protection before evaluating therapeutic claims. The copyright protection for the music created, re-composed, and recorded "for hire" can last 120 years. Clinically validated music can be used as a "stand-alone" non-pharmacological therapy, or can be integrated into disease self-management digital platforms or therapeutic games (Figure 2B). The Digital Millenium Copyright Act from 1998 is the law protecting copyrighted art and works used in digital media against infringement and piracy. In contrast to music, electronic and video games pose complex copyright challenges due to multiple components of art involved in digital technologies (100).

\section{OPPORTUNITIES AND CHALLENGES OF THE COPYRIGHTED COMBINATION THERAPIES}

Using mobile applications, playing electronic games, or listening to music are daily practices of many patients taking medications. As mentioned earlier, games and music target intrinsic motivation and the reward system, becoming useful "personalized medicine" tools to improve patient compliance with their prescribed pharmacotherapies. For chronically ill patients at risk for medication non-adherence, gamification strategies are alternatives to providing external incentives to reinforce taking drugs as prescribed, given that patient motivation may decrease once incentives are discontinued (101). Combination of pharmacotherapy and gamification can improve treatments for chronic diseases with inflammatory components (such as rheumatoid arthritis), which can be lessen by behavioral changes and self-management platforms (102). Given advances in genomics, individuals carrying mutations in susceptibility genes for chronic diseases may benefit from non-pharmacological and behavioral interventions. In addition to encouraging development of preventive medicine strategies, copyrights can also provide incentives to create innovative treatments for rare genetic disorders, for example epileptic encephalopathies.
Since medication non-adherence affects approximately half of the prescribed therapeutics for chronic disorders, drug discovery and clinical development efforts will benefit from applications of the copyrighted combination therapies due to integration of pharmacotherapy outcomes and medication adherence. This aspect becomes important when translating discoveries of new molecular targets into combination therapies: for example, the treatment of epilepsy emphasize needs for network-based polypharmacies (103). Copyrighted therapies may also encourage clinical development of new combination therapies with clinically beneficial compounds existing in public domain (e.g., curcumin), due to the IP exclusivity under the premarket approval (PMA) application. Copyrighted combination products may appeal to developing therapies for neurodegenerative diseases. For example, having 70 years protection of the copyrighted combination therapy for the Alzheimer disease would facilitate balancing decisions between clinical and business objectives related to lengthy clinical trials. Pharmaceutical industry is recognizing both opportunities and challenges in applying mobile medical applications and gamification in patient care $(104,105)$. Since changing patent guidelines can affect drug discovery efforts (106), copyrights can provide incentives to transform generic drugs into innovative treatments of chronic diseases with improve medication adherence and outcomes.

Herein, it is prudent to emphasize challenging times for the regulatory agencies and for those who seek approval/clearance of mobile medical applications and their combinations with pharmacotherapies $(1,107)$. Integrating drugs with devices is commonly associated with combination products such as pen injectors and insulin, transdermal patches, drug-eluting stents, or drug creams with light sources $(108,109)$. The long-term prospects of the copyrighted combination therapies include becoming the combination products. For example, given advancements in medical technologies at the interface of drugs and devices, the FDA established the Office of Combination Products $(110,111)$. Efforts to reach PMA applications for the copyrighted combination products may be incentivized by the long-term exclusivity of specific medical treatment due to the copyright protection. Creation, translational research, and clinical validation of copyrighted non-pharmacological treatments is a long and challenging frontier, requiring cross-technological interactions among pharmaceutical-biotech companies, electronic and mobile devices, and those providing the creative works such as software, video games, or music.

Clinical development of the non-pharmacological therapies like therapeutic games or music, and their combinations with the pharmacotherapies, carry inherent risks related to safety (adverse effects) and efficacy (tolerance, addiction). Developing tolerance to non-pharmacological treatments is unknown, whereas addictive properties of gaming can be addressed by appropriate design features. Current understanding of mechanisms of musicogenic seizures and photosensitive epilepsy can facilitate designing music and games to avoid proconvulsant properties. Incorporation of features such as patient preference to have choices in selecting music for the therapy is offset by unknown variables in response to music due to differences in a patient genetics and personality [for example individual responses to music for pain treatment 
were reported (63)]. Large-scale RCTs will test therapeutic utility of non-pharmacological treatments and their combinations with drugs, and will advance clinical knowledge and design of such innovative treatments for neurological and other chronic medical conditions.

\section{CONCLUSION}

Taken together, creating and developing copyrighted music, games, and medical software to be combined with pharmacotherapies provides an opportunity to deliver novel treatments for patients with neurological and other chronic diseases. Neurosciencecentered, innovative drug-device platforms can facilitate delivery of more personalized and integrated treatments of the target disease and associated comorbidities, resulting in improved therapy outcomes and medication adherence. Mechanism-based combinations of pharmacotherapies with non-pharmacological treatments offer win-win solutions for all health care stake-holders.

\section{ACKNOWLEDGMENTS}

The NIH Grant U01 NS 066991 is acknowledged during Grzegorz Bulaj's sabbatical leave. I would like to thank my colleagues involved in discussions about non-pharmacological treatments in clinical and pharmacy practices. I thank Professors Julie Korenberg, Mark Munger, Harold Wolf, and Steve White, and attorneys Seth Mailhot and Bradley Sanders for their feedback and helpful comments on the manuscript. I thank my family and friends.

\section{SUPPLEMENTARY MATERIAL}

The Supplementary Material for this article can be found online at http://www.frontiersin.org/Journal/10.3389/fneur.2014.00126/ abstract

\section{REFERENCES}

1. Charani E, Castro-Sanchez E, Moore LS, Holmes A. Do smartphone applications in healthcare require a governance and legal framework? It depends on the application! BMC Med (2014) 12:29. doi:10.1186/1741-7015-12-29

2. Food and Drug Administration. Mobile Medical Applications: Guidance for Industry and Food and Drug Administration Staff (2013). Available from: http://www.fda.gov/downloads/MedicalDevices/./UCM263366.pdf

3. de Jongh T, Gurol-Urganci I, Vodopivec-Jamsek V, Car J, Atun R. Mobile phone messaging for facilitating self-management of long-term illnesses. Cochrane Database Syst Rev (2013) 12:CD007459. doi:10.1002/14651858.CD007459. pub2

4. Jones KR, Lekhak N, Kaewluang N. Using mobile phones and short message service to deliver self-management interventions for chronic conditions: a metareview. Worldviews Evid Based Nurs (2014) 11:81-8. doi:10.1111/wvn.12030

5. Hayes DF, Markus HS, Leslie RD, Topol EJ. Personalized medicine: risk prediction, targeted therapies and mobile health technology. BMC Med (2014) 12:37. doi:10.1186/1741-7015-12-37

6. Finitsis DJ, Pellowski JA, Johnson BT. Text message intervention designs to promote adherence to antiretroviral therapy (ART): a meta-analysis of randomized controlled trials. PLoS One (2014) 9:e88166. doi:10.1371/journal.pone. 0088166

7. Free C, Phillips G, Galli L, Watson L, Felix L, Edwards P, et al. The effectiveness of mobile-health technology-based health behaviour change or disease management interventions for health care consumers: a systematic review. PLoS Med (2013) 10:e1001362. doi:10.1371/journal.pmed.1001362

8. Aikens JE, Zivin K, Trivedi R, Piette JD. Diabetes self-management support using mHealth and enhanced informal caregiving. J Diabetes Complications (2014) 28:171-6. doi:10.1016/j.jdiacomp.2013.11.008

9. Dayer L, Heldenbrand S, Anderson P, Gubbins PO, Martin BC. Smartphone medication adherence apps: potential benefits to patients and providers. J Am Pharm Assoc (2003) 53:172-81. doi:10.1331/JAPhA.2013.12202
10. Vervloet M, van Dijk L, Santen-Reestman J, van Vlijmen B, van Wingerden P, Bouvy ML, et al. SMS reminders improve adherence to oral medication in type 2 diabetes patients who are real time electronically monitored. Int J Med Inform (2012) 81:594-604. doi:10.1016/j.ijmedinf.2012.05.005

11. Reynoldson C, Stones C, Allsop M, Gardner P, Bennett MI, Closs SJ, et al. Assessing the quality and usability of smartphone apps for pain self-management. Pain Med (2014) 15(6):898-909. doi:10.1111/pme.12327

12. Wallace LS, Dhingra LK. A systematic review of smartphone applications for chronic pain available for download in the United States. J Opioid Manag (2014) 10:63-8. doi:10.5055/jom.2014.0193

13. Marcano Belisario JS, Huckvale K, Greenfield G, Car J, Gunn LH. Smartphone and tablet self management apps for asthma. Cochrane Database Syst Rev (2013) 11:CD010013. doi:10.1002/14651858.CD010013.pub2

14. Andrews G, Cuijpers P, Craske MG, McEvoy P, Titov N. Computer therapy for the anxiety and depressive disorders is effective, acceptable and practical health care: a meta-analysis. PLoS One (2010) 5:e13196. doi:10.1371/journal.pone. 0013196

15. Donker T, Petrie K, Proudfoot J, Clarke J, Birch MR, Christensen H. Smartphones for smarter delivery of mental health programs: a systematic review. J Med Internet Res (2013) 15:e247. doi:10.2196/jmir.2791

16. Quinn CC, Clough SS, Minor JM, Lender D, Okafor MC, Gruber-Baldini A. WellDoc mobile diabetes management randomized controlled trial: change in clinical and behavioral outcomes and patient and physician satisfaction. Diabetes Technol Ther (2008) 10:160-8. doi:10.1089/dia.2008.0283

17. Quinn CC, Gruber-Baldini AL, Shardell M, Weed K, Clough SS, Peeples $\mathrm{M}$, et al. Mobile diabetes intervention study: testing a personalized treatment/behavioral communication intervention for blood glucose control. Contemp Clin Trials (2009) 30:334-46. doi:10.1016/j.cct.2009.02.004

18. Quinn CC, Shardell MD, Terrin ML, Barr EA, Ballew SH, Gruber-Baldini AL. Cluster-randomized trial of a mobile phone personalized behavioral intervention for blood glucose control. Diabetes Care (2011) 34:1934-42. doi: $10.2337 / \mathrm{dc} 11-0366$

19. Shuren J. The FDA's role in the development of medical mobile applications. Clin Pharmacol Ther (2014) 95:485-8. doi:10.1038/clpt.2014.45

20. Hieftje K, Edelman EJ, Camenga DR, Fiellin LE. Electronic media-based health interventions promoting behavior change in youth: a systematic review. JAMA Pediatr (2013) 167:574-80. doi:10.1001/jamapediatrics.2013.1095

21. Baranowski T, Buday R, Thompson D, Lyons EJ, Lu AS, Baranowski J. Developing games for health behavior change: getting started. Games Health J (2013) 2:183-90. doi:10.1089/g4h.2013.0048

22. Bruggers CS, Altizer RA, Kessler RR, Caldwell CB, Coppersmith K, Warner L, et al. Patient-empowerment interactive technologies. Sci Transl Med (2012) 4:152s116. doi:10.1126/scitranslmed.3004009

23. Lieberman DA. Video games for diabetes self-management: examples and design strategies. J Diabetes Sci Technol (2012) 6:802-6. doi:10.1177/ 193229681200600410

24. Esculier JF, Vaudrin J, Beriault P, Gagnon K, Tremblay LE. Home-based balance training programme using Wii fit with balance board for Parkinsons's disease: a pilot study. J Rehabil Med (2012) 44:144-50. doi:10.2340/16501977-0922

25. Russoniello CV, Fish M, O’Brien K. The efficacy of casual videogame play in reducing clinical depression: a randomized controlled study. Games Health J (2013) 2:341-6. doi:10.1089/g4h.2013.0010

26. Kottink AIR, Prange GB, Krabben T, Rietman JS, Buurke JH. Gaming and conventional exercise for improvement of arm function after stroke: a randomized controlled pilot study. Games Health J (2014) 3:184-91. doi:10.1089/g4h.2014. 0026

27. Beale IL, Kato PM, Marin-Bowling VM, Guthrie N, Cole SW. Improvement in cancer-related knowledge following use of a psychoeducational video game for adolescents and young adults with cancer. J Adolesc Health (2007) 41:263-70. doi:10.1016/j.jadohealth.2007.04.006

28. Kato PM, Cole SW, Bradlyn AS, Pollock BH. A video game improves behavioral outcomes in adolescents and young adults with cancer: a randomized trial. Pediatrics (2008) 122:e305-17. doi:10.1542/peds.2007-3134

29. Merry SN, Stasiak K, Shepherd M, Frampton C, Fleming T, Lucassen MF. The effectiveness of SPARX, a computerised self help intervention for adolescents seeking help for depression: randomised controlled non-inferiority trial. BMJ (2012) 344:e2598. doi:10.1136/bmj.e2598

30. Anguera JA, Boccanfuso J, Rintoul JL, Al-Hashimi O, Faraji F, Janowich J, et al. Video game training enhances cognitive control in older adults. Nature (2013) 501:97-101. doi:10.1038/nature12486 
31. Hieftje K, Rosenthal MS, Camenga DR, Edelman EJ, Fiellin LE. A qualitative study to inform the development of a video game for adolescent HIV prevention. Games Health J (2012) 1:294-8. doi:10.1089/g4h.2012.0025

32. Simons M, Chinapaw MJ, van de Bovenkamp M, de Boer MR, Seidell JC, Brug $\mathrm{J}$, et al. Active video games as a tool to prevent excessive weight gain in adolescents: rationale, design and methods of a randomized controlled trial. BMC Public Health (2014) 14:275. doi:10.1186/1471-2458-14-275

33. Koelsch S. Brain correlates of music-evoked emotions. Nat Rev Neurosci (2014) 15:170-80. doi:10.1038/nrn3666

34. Chanda ML, Levitin DJ. The neurochemistry of music. Trends Cogn Sci (2013) 17(4):179-93. doi:10.1016/j.tics.2013.02.007

35. Fancourt D, Ockelford A, Belai A. The psychoneuroimmunological effects of music: a systematic review and a new model. Brain Behav Immun (2014) 36:15-26. doi:10.1016/j.bbi.2013.10.014

36. Dastgheib SS, Layegh P, Sadeghi R, Foroughipur M, Shoeibi A, Gorji A. The effects of Mozart's music on interictal activity in epileptic patients: systematic review and meta-analysis of the literature. Curr Neurol Neurosci Rep (2014) 14:420. doi:10.1007/s11910-013-0420-x

37. Lin L, Yang R. Using music to treat epilepsy in children: a review. Music Med (2013) 5:242-7. doi:10.1177/1943862113500506

38. Hughes JR, Daaboul Y, Fino JJ, Shaw GL. The "Mozart effect" on epileptiform activity. Clin Electroencephalogr (1998) 29:109-19. doi:10.1177/ 155005949802900301

39. Lin LC, Lee WT, Wu HC, Tsai CL, Wei RC, Jong YJ, et al. Mozart K.448 and epileptiform discharges: effect of ratio of lower to higher harmonics. Epilepsy Res (2010) 89:238-45. doi:10.1016/j.eplepsyres.2010.01.007

40. Lin LC, Lee WT, Wu HC, Tsai CL, Wei RC, Mok HK, et al. The longterm effect of listening to Mozart K.448 decreases epileptiform discharges in children with epilepsy. Epilepsy Behav (2011) 21:420-4. doi:10.1016/j.yebeh. 2011.05.015

41. Lin LC, Lee MW, Wei RC, Mok HK, Wu HC, Tsai CL, et al. Mozart k.545 mimics Mozart k.448 in reducing epileptiform discharges in epileptic children. Evid Based Complement Alternat Med (2012) 2012:607517. doi:10.1155/2012/ 607517

42. Lin LC, Chiang CT, Lee MW, Mok HK, Yang YH, Wu HC, et al. Parasympathetic activation is involved in reducing epileptiform discharges when listening to Mozart music. Clin Neurophysiol (2013) 124:1528-35. doi:10.1016/j.clinph. 2013.02.021

43. Lin LC, Lee MW, Wei RC, Mok HK, Yang RC. Mozart K.448 listening decreased seizure recurrence and epileptiform discharges in children with first unprovoked seizures: a randomized controlled study. BMC Complement Altern Med (2014) 14:17. doi:10.1186/1472-6882-14-17

44. Bodner M, Turner RP, Schwacke J, Bowers C, Norment C. Reduction of seizure occurrence from exposure to auditory stimulation in individuals with neurological handicaps: a randomized controlled trial. PLoS One (2012) 7:e45303. doi:10.1371/journal.pone.0045303

45. Bernatzky G, Presch M, Anderson M, Panksepp J. Emotional foundations of music as a non-pharmacological pain management tool in modern medicine. Neurosci Biobehav Rev (2011) 35:1989-99. doi:10.1016/j.neubiorev. 2011.06.005

46. Cole LC, Lobiondo-Wood G. Music as an adjuvant therapy in control of pain and symptoms in hospitalized adults: a systematic review. Pain Manag Nurs (2014) 15:406-25. doi:10.1016/j.pmn.2012.08.010

47. Guetin S, Ginies P, Siou DK, Picot MC, Pommie C, Guldner E, et al. The effects of music intervention in the management of chronic pain: a singleblind, randomized, controlled trial. Clin J Pain (2012) 28:329-37. doi:10.1097/ AJP.0b013e31822be973

48. Garza-Villarreal EA, Wilson AD, Vase L, Brattico E, Barrios FA, Jensen TS, et al. Music reduces pain and increases functional mobility in fibromyalgia. Front Psychol (2014) 5:90. doi:10.3389/fpsyg.2014.00090

49. Rodriguez-Fornells A, Rojo N, Amengual JL, Ripolles P, Altenmuller E, Munte TF. The involvement of audio-motor coupling in the music-supported therapy applied to stroke patients. Ann N Y Acad Sci (2012) 1252:282-93. doi:10.1111/j.1749-6632.2011.06425.x

50. Altenmuller E, Schlaug G. Neurobiological aspects of neurologic music therapy. Music Med (2013) 5:210-6. doi:10.1177/1943862113505328

51. Ueda T, Suzukamo Y, Sato M, Izumi S. Effects of music therapy on behavioral and psychological symptoms of dementia: a systematic review and metaanalysis. Ageing Res Rev (2013) 12:628-41. doi:10.1016/j.arr.2013.02.003
52. Vasionyte I, Madison G. Musical intervention for patients with dementia: a meta-analysis. J Clin Nurs (2013) 22:1203-16. doi:10.1111/jocn. 12166

53. Erkkila J, Punkanen M, Fachner J, Ala-Ruona E, Pontio I, Tervaniemi M, et al. Individual music therapy for depression: randomised controlled trial. Br J Psychiatry (2011) 199:132-9. doi:10.1192/bjp.bp.110.085431

54. Bradt J, Dileo C, Shim M. Music interventions for preoperative anxiety. Cochrane Database Syst Rev (2013) 6:CD006908. doi:10.1002/14651858. CD006908.pub2

55. Chlan LL, Weinert CR, Heiderscheit A, Tracy MF, Skaar DJ, Guttormson JL, et al. Effects of patient-directed music intervention on anxiety and sedative exposure in critically ill patients receiving mechanical ventilatory support: a randomized clinical trial. JAMA (2013) 309:2335-44. doi:10.1001/jama.2013.5670

56. Robb SL, Burns DS, Stegenga KA, Haut PR, Monahan PO, Meza J, et al. Randomized clinical trial of therapeutic music video intervention for resilience outcomes in adolescents/young adults undergoing hematopoietic stem cell transplant: a report from the children's oncology group. Cancer (2014) 120:909-17. doi:10.1002/cncr.28355

57. Osterberg L, Blaschke T. Adherence to medication. N Engl J Med (2005) 353:487-97. doi:10.1056/NEJMra050100

58. Brown MT, Bussell JK. Medication adherence: WHO cares? Mayo Clin Proc (2011) 86:304-14. doi:10.4065/mcp.2010.0575

59. World Health Organization. Adherence to Long Term Therapies: Evidence for Action. Geneva: World Health Organization (2003).

60. Forissier T, Firlik K. Estimated Annual Pharmaceutical Revenue Loss Due to Medication Non-Adherence. Paris: Capgemini Consulting (2012). p. 1-20.

61. Landwehr B. Big games: one company's experience with gamification of health. Games Health J (2014) 3:64-6. doi:10.1089/g4h.2014.0007

62. Bradshaw DH, Chapman CR, Jacobson RC, Donaldson GW. Effects of music engagement on responses to painful stimulation. Clin J Pain (2012) 28:418-27. doi:10.1097/AJP.0b013e318236c8ca

63. Bradshaw DH, Donaldson GW, Jacobson RC, Nakamura Y, Chapman CR. Individual differences in the effects of music engagement on responses to painful stimulation. J Pain (2011) 12:1262-73. doi:10.1016/j.jpain.2011.08.010

64. Chaparro LE, Wiffen PJ, Moore RA, Gilron I. Combination pharmacotherapy for the treatment of neuropathic pain in adults. Cochrane Database Syst Rev (2012) 7:CD008943. doi:10.1002/14651858.CD008943.pub2

65. Naylor MR, Naud S, Keefe FJ, Helzer JE. Therapeutic interactive voice response (TIVR) to reduce analgesic medication use for chronic pain management. J Pain (2010) 11:1410-9. doi:10.1016/j.jpain.2010.03.019

66. Moon H, Baek Y. Exploring variables affecting player's intrinsic motivation in educational games. The 17th International Conference on Computers in Education. Hong Kong: Asia-Pacific Society for Computers in Education (2009).

67. Cole SW, Yoo DJ, Knutson B. Interactivity and reward-related neural activation during a serious videogame. PLoS One (2012) 7:e33909. doi:10.1371/journal. pone.0033909

68. Katsyri J, Hari R, Ravaja N, Nummenmaa L. Just watching the game ain't enough: striatal fMRI reward responses to successes and failures in a video game during active and vicarious playing. Front Hum Neurosci (2013) 7:278. doi:10.3389/fnhum.2013.00278

69. Koepp MJ, Gunn RN, Lawrence AD, Cunningham VJ, Dagher A, Jones T, et al. Evidence for striatal dopamine release during a video game. Nature (1998) 393:266-8. doi:10.1038/30498

70. Gold BP, Frank MJ, Bogert B, Brattico E. Pleasurable music affects reinforcement learning according to the listener. Front Psychol (2013) 4:541. doi:10.3389/fpsyg.2013.00541

71. Salimpoor VN, Benovoy M, Larcher K, Dagher A, Zatorre RJ. Anatomically distinct dopamine release during anticipation and experience of peak emotion to music. Nat Neurosci (2011) 14:257-62. doi:10.1038/nn.2726

72. Salimpoor VN, van den Bosch I, Kovacevic N, McIntosh AR, Dagher A, Zatorre RJ. Interactions between the nucleus accumbens and auditory cortices predict music reward value. Science (2013) 340:216-9. doi:10.1126/science.1231059

73. Osuch EA, Bluhm RL, Williamson PC, Theberge J, Densmore M, Neufeld RW. Brain activation to favorite music in healthy controls and depressed patients. Neuroreport (2009) 20:1204-8. doi:10.1097/WNR.0b013e32832f4da3

74. Salamone JD, Correa M. The mysterious motivational functions of mesolimbic dopamine. Neuron (2012) 76:470-85. doi:10.1016/j.neuron.2012.10.021

75. Howe MW, Tierney PL, Sandberg SG, Phillips PE, Graybiel AM. Prolonged dopamine signalling in striatum signals proximity and value of distant rewards. Nature (2013) 500:575-9. doi:10.1038/nature12475 
76. Han DH, Renshaw PF, Sim ME, Kim JI, Arenella LS, Lyoo IK. The effect of internet video game play on clinical and extrapyramidal symptoms in patients with schizophrenia. Schizophr Res (2008) 103:338-40. doi:10.1016/j.schres. 2008.01.026

77. Pompeu JE, Arduini LA, Botelho AR, Fonseca MB, Pompeu SM, Torriani-Pasin $\mathrm{C}$, et al. Feasibility, safety and outcomes of playing Kinect Adventures! ${ }^{\mathrm{TM}}$ for people with Parkinson's disease: a pilot study. Physiotherapy (2014) 100:162-8. doi:10.1016/j.physio.2013.10.003

78. Mehndiratta P, Sajatovic M. Treatments for patients with comorbid epilepsy and depression: a systematic literature review. Epilepsy Behav (2013) 28:36-40. doi:10.1016/j.yebeh.2013.03.029

79. Schmidt D, Sillanpaa M. Evidence-based review on the natural history of the epilepsies. Curr Opin Neurol (2012) 25:159-63. doi:10.1097/WCO. 0b013e3283507e73

80. Faught E, Duh MS, Weiner JR, Guerin A, Cunnington MC. Nonadherence to antiepileptic drugs and increased mortality: findings from the RANSOM study. Neurology (2008) 71:1572-8. doi:10.1212/01.wnl. 0000319693.10338.b9

81. Ettinger AB, Manjunath R, Candrilli SD, Davis KL. Prevalence and cost of nonadherence to antiepileptic drugs in elderly patients with epilepsy. Epilepsy Behav (2009) 14:324-9. doi:10.1016/j.yebeh.2008.10.021

82. Manjunath R, Davis KL, Candrilli SD, Ettinger AB. Association of antiepileptic drug nonadherence with risk of seizures in adults with epilepsy. Epilepsy Behav (2009) 14(2):372-8. doi:10.1016/j.yebeh.2008.12.006

83. Cardamone L, Salzberg MR, O’Brien TJ, Jones NC. Antidepressant therapy in epilepsy: can treating the comorbidities affect the underlying disorder? $\mathrm{Br}$ J Pharmacol (2013) 168:1531-54. doi:10.1111/bph.12052

84. Lin LC, Lee WT, Wang CH, Chen HL, Wu HC, Tsai CL, et al. Mozart K.448 acts as a potential add-on therapy in children with refractory epilepsy. Epilepsy Behav (2011) 20:490-3. doi:10.1016/j.yebeh.2010.12.044

85. Bozzi Y, Borrelli E. The role of dopamine signaling in epileptogenesis. Front Cell Neurosci (2013) 7:157. doi:10.3389/fncel.2013.00157

86. Odano I, Varrone A, Savic I, Ciumas C, Karlsson P, Jucaite A, et al. Quantitative PET analyses of regional [11C]PE2I binding to the dopamine transporter application to juvenile myoclonic epilepsy. Neuroimage (2012) 59:3582-93. doi:10.1016/j.neuroimage.2011.10.067

87. Rocha L, Alonso-Vanegas M, Villeda-Hernandez J, Mujica M, CisnerosFranco JM, Lopez-Gomez M, et al. Dopamine abnormalities in the neocortex of patients with temporal lobe epilepsy. Neurobiol Dis (2012) 45:499-507. doi:10.1016/j.nbd.2011.09.006

88. Werhahn KJ, Landvogt C, Klimpe S, Buchholz HG, Yakushev I, Siessmeier T, et al. Decreased dopamine D2/D3-receptor binding in temporal lobe epilepsy: an [18F]fallypride PET study. Epilepsia (2006) 47:1392-6. doi:10.1111/j.15281167.2006.00561.x

89. Allendorfer JB, Heyse H, Mendoza L, Nelson EB, Eliassen JC, Storrs JM, et al. Physiologic and cortical response to acute psychosocial stress in left temporal lobe epilepsy - a pilot cross-sectional fMRI study. Epilepsy Behav (2014) 36C:115-23. doi:10.1016/j.yebeh.2014.05.003

90. Schmitt FC, Voges J, Heinze HJ, Zaehle T, Holtkamp M, Kowski AB. Safety and feasibility of nucleus accumbens stimulation in five patients with epilepsy. J Neurol (2014). doi:10.1007/s00415-014-7364-1

91. Raglio A, Farina E, Giovagnoli AR. Can music therapy alleviate psychological, cognitive, and behavioral impairment in epilepsy? Epilepsy Behav (2014) 31:7-8. doi:10.1016/j.yebeh.2013.10.008

92. Modi AC, Rausch JR, Glauser TA. Early pediatric antiepileptic drug nonadherence is related to lower long-term seizure freedom. Neurology (2014) 82:671-3. doi:10.1212/WNL.0000000000000147

93. Tavakoli F, Hoseini SE, Mokhtari M, Vahdati A, Razmi N, Vessal M. Role of music in morphine rewarding effects in mice using conditioned place preference method. Neuro Endocrinol Lett (2012) 33:709-12.

94. Lin LC, Juan CT, Chang HW, Chiang CT, Wei RC, Lee MW, et al. Mozart K.448 attenuates spontaneous absence seizure and related high-voltage rhythmic spike discharges in Long Evans rats. Epilepsy Res (2013) 104:234-40. doi:10.1016/j.eplepsyres.2012.11.005

95. Tasset I, Quero I, Garcia-Mayorgaz AD, del Rio MC, Tunez I, Montilla P. Changes caused by haloperidol are blocked by music in Wistar rat. J Physiol Biochem (2012) 68:175-9. doi:10.1007/s13105-011-0129-8
96. Lu Y, Liu M, Shi S, Jiang H, Yang L, Liu X, et al. Effects of stress in early life on immune functions in rats with asthma and the effects of music therapy. J Asthma (2010) 47:526-31. doi:10.3109/02770901003801964

97. Rauscher FH, Robinson KD, Jens JJ. Improved maze learning through early music exposure in rats. Neurol Res (1998) 20:427-32.

98. Rauscher FH, Shaw GL, Ky KN. Listening to Mozart enhances spatial-temporal reasoning: towards a neurophysiological basis. Neurosci Lett (1995) 185:44-7. doi:10.1016/0304-3940(94)11221-4

99. Aoun P, Jones T, Shaw GL, Bodner M. Long-term enhancement of maze learning in mice via a generalized Mozart effect. Neurol Res (2005) 27:791-6. doi:10.1179/016164105X63647

100. Ramos A, Lopez A, Rodrigez A, Meng T, Abrams S. The Legal Status of Video Games: Comparative Analysis in National Approaches. World Intellectual Property Organization (2013). p. 1-96. Available from: http://www.wipo. int/export/sites/www/copyright/en/activities/pdf/comparative_analysis_on_ video_games.pdf

101. DeFulio A, Silverman K. The use of incentives to reinforce medication adherence. Prev Med (2012) 55(Suppl):S86-94. doi:10.1016/j.ypmed.2012.04.017

102. Brady TJ, Murphy L, Beauchesne D, Bhalakia A, Chervin D, Daniels B, et al. Sorting Through the Evidence for the Arthritis Self-Management Program and the Chronic Disease Self-management Program. Atlanta: Center for Disease Control and Prevention (2011). p. 1-24.

103. White HS, Loscher W. Searching for the ideal antiepileptogenic agent in experimental models: single treatment versus combinatorial treatment strategies. Neurotherapeutics (2014) 11:373-84. doi:10.1007/s13311-013-0250-1

104. Bucklen KW, Abbott BM. Promise and challenges with the use of mobile applications to support and improve patient care: an industry perspective. Clin Pharmacol Ther (2014) 95:469-71. doi:10.1038/clpt.2014.34

105. Robinson R. What's in a Game? Better Health Outcomes. PharmaVOICE (2014). Available from: http://www.pharmavoice.com/archives/article.esiml?id=2841

106. Harrison C. Patenting natural products just got harder. Nat Biotechnol (2014) 32:403-4. doi:10.1038/nbt0514-403a

107. Yetisen AK, Martinez-Hurtado JL, da Cruz Vasconcellos F, Simsekler MC, Akram MS, Lowe CR. The regulation of mobile medical applications. Lab Chip (2014) 14:833-40. doi:10.1039/c3lc51235e

108. Couto DS, Perez-Breva L, Saraiva P, Cooney CL. Lessons from innovation in drug-device combination products. Adv Drug Deliv Rev (2012) 64:69-77. doi:10.1016/j.addr.2011.10.008

109. Hupcey MA, Ekins S. Improving the drug selection and development process for combination devices. Drug Discov Today (2007) 12:844-52. doi:10.1016/j. drudis.2007.07.020

110. Food and Drug Administartion. Early Development Considerations for Innovative Combination Products, Guidance for Industry and FDA Staff (2006). Available from: http://www.fda.gov/regulatoryinformation/guidances/ucm 126050 . htm

111. Food and Drug Administration. Office of Combination Products, Performance Report FY 2012 (2012). Available from: http://www.fda.gov/AboutFDA/ ReportsManualsForms/Reports/PerformanceReports/CombinationProducts/ ucm365878.htm

Conflict of Interest Statement: Grzegorz Bulaj is a co-inventor of the patent "Disease Therapy Game Technology," owned by the University of Utah. Grzegorz Bulaj is a scientific cofounder of NeuroAdjuvants, Inc., a company focused on developing peptide-based drugs that cross the blood-brain barrier for the treatments of epilepsy and pain.

Received: 10 May 2014; accepted: 27 June 2014; published online: 14 July 2014 Citation: Bulaj $G$ (2014) Combining non-pharmacological treatments with pharmacotherapies for neurological disorders: a unique interface of the brain, drug-device, and intellectual property. Front. Neurol. 5:126. doi: 10.3389/fneur.2014.00126

This article was submitted to Epilepsy, a section of the journal Frontiers in Neurology. Copyright (c) 2014 Bulaj. This is an open-access article distributed under the terms of the Creative Commons Attribution License (CC BY). The use, distribution or reproduction in other forums is permitted, provided the original author(s) or licensor are credited and that the original publication in this journal is cited, in accordance with accepted academic practice. No use, distribution or reproduction is permitted which does not comply with these terms. 